\title{
New Insights of Anti-Hyperglycemic Agents and Traditional Chinese Medicine on Gut Microbiota in Type 2 Diabetes
}

\section{Yanxia Chen (1) \\ Mian Wang (D)}

Department of Endocrinology, The Second Hospital of Hebei Medical University, Shijiazhuang, Hebei, 05005I, People's Republic of China
Correspondence: Mian Wang Department of Endocrinology, The Second Hospital of Hebei Medical University, 215 Hepingxi Road, Shijiazhuang, Hebei, 05005I, People's Republic of China

Email wangmian66@sina.com

\begin{abstract}
Type 2 diabetes mellitus (T2DM) is a widespread metabolic disease characterized by chronic hyperglycemia. Human microbiota, which is regarded as a "hidden organ", plays an important role in the initiation and development of T2DM. In addition, antihyperglycemic agents and traditional Chinese medicine may affect the composition of gut microbiota and consequently improve glucose metabolism. However, the relationship between gut microbiota, T2DM and anti-hyperglycemic agents or traditional Chinese medicine is poorly understood. In this review, we summarized pre-clinical and clinical studies to elucidate the possible underlying mechanism. Some anti-hyperglycemic agents and traditional Chinese medicine may partly exert hypoglycemic effects by altering the gut microbiota composition in ways that reduce metabolic endotoxemia, maintain the integrity of intestinal mucosal barrier, promote the production of short-chain fatty acids (SCFAs), decrease trimethylamine-N-oxide (TMAO) and regulate bile acid metabolism. In conclusion, gut microbiota may provide some new therapeutic targets for treatment of patients with diabetes mellitus.
\end{abstract}

Keywords: gut microbiota, anti-hyperglycemic agents, traditional Chinese medicine, type 2 diabetes mellitus

\section{Introduction}

Diabetes mellitus (DM), which is contributed to genetic and/or environmental factors, is the most prevalent metabolic disease worldwide characterized by chronic hyperglycemia. Type 2 diabetes mellitus (T2DM), which results from insulin resistance and/or impaired insulin secretion, accounts for more than $90 \%$ of patients with DM. Long-term hyperglycemia can result in detrimental micro- and macrovascular complications, involving many organs and systems, especially kidneys, nervous system, eyes and blood vessel. ${ }^{1}$

Tens of trillions of microorganisms indigenously colonize the gastrointestinal tract immediately after birth, collectively termed as gut microbiota. Gut microbiota is a highly complex and dynamic microbial ecosystem and may be regarded as a "hidden organ". Human microbiota, which is considered as a metabolic organ, can perform diverse physiological functions to maintain homeostasis in health. ${ }^{2}$ It is estimated that the number of microbial genes approximately exceeds 100-fold higher than that of human genome. The gut microbiota, also considered as the "second genome" of the host, provides humans with additional biological and metabolic functions that cannot be performed by the host. ${ }^{3}$ The composition of 
the gut microbiota is influenced by several variables including diet, sex, age, lifestyle, environment, geographical location and genetic background. ${ }^{4}$ The gut microbiota is dominated by four phyla: Firmicutes (Gram-positive, 60-65\%), Bacteroidetes (Gram-negative, 20-25\%), Proteobacteria (Gram-negative, 5-10\%), Actinobacteria (Gram-positive, 3\%). ${ }^{5}$ Growing evidences suggest that the perturbation of normal intestinal microbiota composition, also termed as dysbiosis, may break the homeostasis and result in a variety of common metabolic diseases, including diabetes and diabetic complications. ${ }^{6,7}$

Over the last few decades, a myriad of original research indicates that there is an association between gut microbiota and T2DM. In previous years, some reviews published have reported the interaction between anti-hyperglycemic agents and gut microbiota. ${ }^{8,9}$ The association between human microbiome and traditional Chinese medicine on healthcare and cancer treatment has gained attention in recent years, ${ }^{10,11}$ but reviews on the association between antidiabetic effect of the traditional Chinese medicine and gut microbiota are insufficient. Accordingly, we summarized the latest literatures and explored the potential mechanisms of how antihyperglycemic agents and traditional Chinese medicine influenced the gut microbiota, which might provide some new therapeutic targets of T2DM.

\section{Gut Microbiota and T2DM}

Increasing clinical and animal researches have revealed the important role of gut microbiota dysbiosis in the initiation and development of T2DM. ${ }^{7,12}$ Given that hyperglycemia also affect bacterial composition, ${ }^{13,14}$ the gut microbiota and diabetes have a reciprocally regulatory relationship. ${ }^{15}$

\section{Metabolic Endotoxemia}

Several studies have determined that the gut microbiota dysbiosis leads to insulin resistance and T2DM through several mechanisms including lipopolysaccharide (LPS)mediated metabolic endotoxemia (Figure 1A). LPS, which is a major component of the outer membrane of the Gramnegative bacteria, contributes to development of low-grade chronic inflammation known as metabolic endotoxemia. ${ }^{16}$ High-fat diet (HFD) may increase LPS-enriched intestinal microbiota and consequently elevate the plasma concentration of LPS. ${ }^{17}$ In the intestinal tract, LPS triggers the dysfunction of intestinal barrier and increases gut permeability. Excessive LPS enters the blood and translocates across the damaged intestinal barrier, leading to the low-grade inflammatory injury of intestinal epithelium. ${ }^{18} \mathrm{~A}$ great deal of researches have determined that the low-grade inflammation is associated with insulin resistance and T2DM. ${ }^{19}$ A typical LPS molecule is composed of three different constituents: a highly variable $\mathrm{O}$-antigen constituted of repeating oligosaccharide units, a core oligosaccharide and lipid A. ${ }^{20}$ Lipid $\mathrm{A}$ is one of the core structures of bacterial LPS and is responsible for much of LPS's toxicity. Lipid A, which is an amphipathic glycolipid domain, triggers strong immune and inflammatory responses by tightly binding to Toll-like receptors (TLRs). ${ }^{21}$ Most TLRs coordinate a series of proinflammatory signaling cascades through the Myeloid differentiation primary response 88 (MyD88)-dependent pathway. $^{22-24}$ The activated MyD88 then stimulates the proinflammatory cytokines expression and secretion to induce the low-grade inflammatory, such as IL-1 receptor-associated kinase (IRAK), TNF receptor-associated factor (TRAF6), transforming growth factor B-associated kinase 1 (TAK1), Monocyte Chemoattractant Protein-1 (MCP-1), TNF- $\alpha$ and JNK and IKK complexes. JNK and IKK complexes, which can induce serine phosphorylation of insulin receptor substrate (IRS), inhibit insulin signaling and result in insulin resistance. $^{25}$

\section{Gut Permeability}

An amount of investigation shows that the intestinal mucosal barrier, which can prevent bacteria and toxins from reaching the circulation, plays an important role in maintaining intestinal homeostasis. The intestinal mucosal barrier is composed of the intestinal epithelium cells (IECs), the tight junction proteins between IECs and their protective mucous layer. ${ }^{26}$ Under the influence of HFD, inflammatory stimulation and other factors, the intestinal barrier would be destroyed and the intestinal mucosa permeability would be enhanced, which in turn increases excessive inflammatory cytokine and metabolic endotoxemia. ${ }^{27}$ Thereby, the disruption of the intestinal barrier or the imbalance of gut microbiota would aggravate the progress of diabetes and its complications. ${ }^{28}$ Intestinal permeability is usually regulated by tight junction proteins, such as zonula occludens-1 (ZO$1)$, occludin, and claudin-1. Recently, prebiotic or exogenous glucagon-like peptide-2 (GLP-2) treatment significantly improves tight junctions and reduces gut permeability by increasing intestinal GLP-2 production in obese and diabetic mice. $^{29,30}$ GLP-2 is a 33-amino acid peptide derived from proteolytic cleavage of proglucagon in enteroendocrine $\mathrm{L}$ cells. Moreover, blockade of endocannabinoid (eCB) 


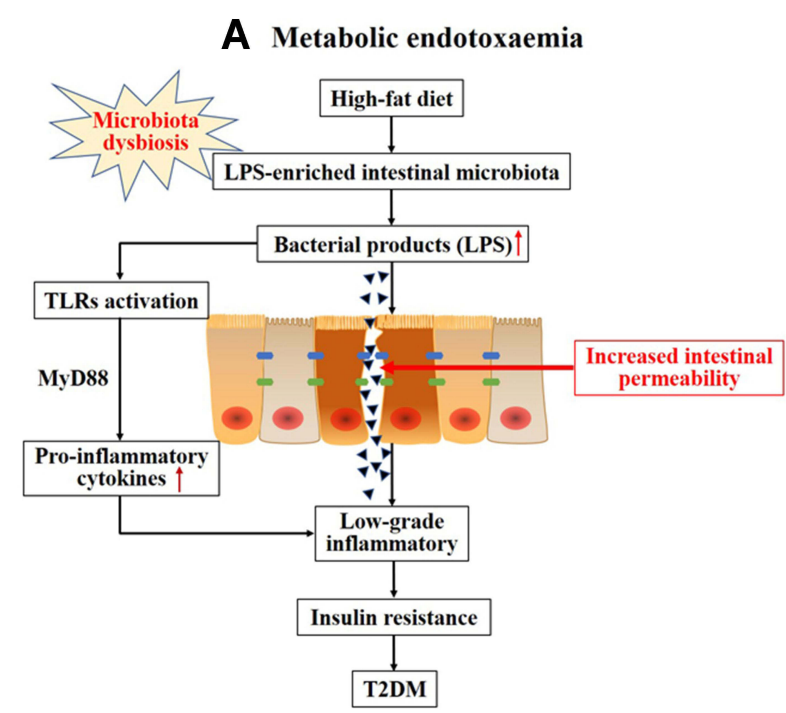

C Trimethylamine-N-Oxide (TMAO)

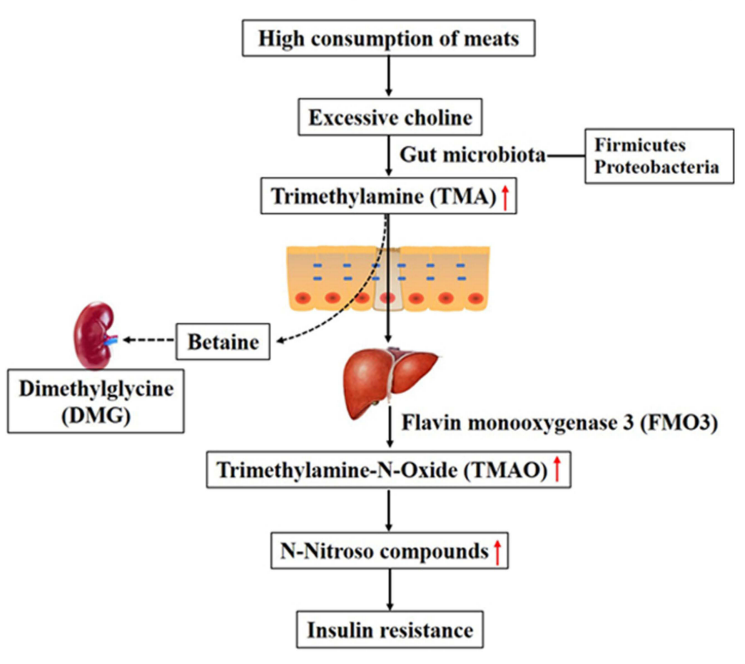

B Short-chain fatty acids (SCFAs)
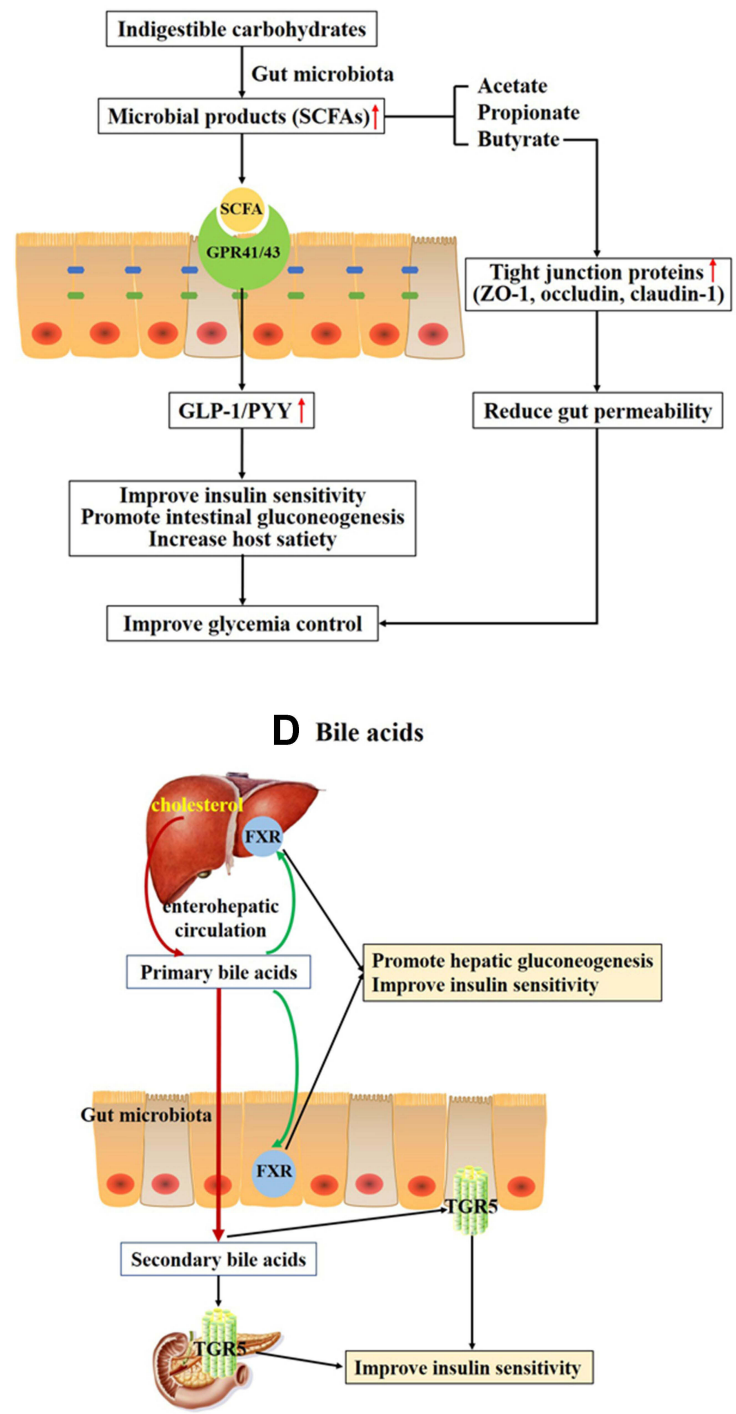

Figure I Overall scheme showing the potential mechanisms linking gut microbiota and the development of T2DM. (A) High-fat diet increases LPS-enriched intestinal microbiota, resulting in elevating the concentration of LPS. Excessive LPS triggers the dysfunction of intestinal barrier and increases intestinal permeability, then leading to the low-grade inflammatory through binding and activating Toll-like receptors (TLRs). Chronic low-grade inflammation is associated with insulin resistance and type 2 diabetes. (B) Indigestible carbohydrates were hydrolyzed and fermented to produce short-chain fatty acids (SCFAs), such as acetate, propionate and butyrate. SCFAs activate G-protein coupled receptors 4 I and 43 (GPR4I/43) to stimulate production of glucagon-like peptide-I (GLP-I) and the intestinal peptide YY (PYY), which improve insulin secretion and promote intestinal gluconeogenesis. (C) High consumption of meats leads to produce excessive choline. Choline is metabolized to produce trimethylamine (TMA) by gut microbiota, primarily the Firmicutes and Proteobacteria phyla. TMA readily passes the intestinal wall to form trimethylamine-N-Oxide (TMAO). TMAO promotes insulin resistance through forming N-Nitroso compounds. Choline may escape microbial degradation and converted into betaine and further metabolites (eg, dimethylglycine (DMG)) which have detrimental osmotic effects by mammalian mitochondrial pathways in kidney. (D) Primary bile acids are synthesized from cholesterol in hepatocytes. Secondary bile acids are derived from primary bile acids, mainly by the biosynthetic capabilities of few gut microbes. The primary BAs can regulate hepatic glucose metabolism and insulin sensitivity through activating the nuclear farnesoid X receptors (FXR) in liver and intestine. Secondary bile acids can stimulate GLP-I secretion from L-cells in the intestine to improve insulin sensitivity through binding to G-protein-coupled bile acid receptor I (TGR5) in enteroendocrine cells and pancreatic $\beta$-cells.

system could improve the gut barrier and reduce metabolic endotoxemia through increasing tight junction proteins. ${ }^{31}$

\section{Short-Chain Fatty Acids (SCFAs)}

Gut microbiota is able to hydrolyze and ferment the indigestible carbohydrates to yield important microbial products, such as SCFAs, trimethylamine N-oxide (TMAO), amino acids and bile acids (BAs). ${ }^{32}$ These metabolites, particularly SCFAs, are involved in the regulation of glucose and energy metabolism (Figure 1B). SCFAs, such as acetate, propionate and butyrate, have considerable effects on regulating pancreatic $\beta$ cell proliferation, insulin biosynthesis, ${ }^{33}$ maintaining gut epithelial barrier function, ${ }^{34}$ anti-inflammatory functions and so on. The 
principal receptors of gut microbiota-derived SCFAs are G-protein coupled receptors 43 and 41 (GPR43/41), which are expressed in the islets of Langerhans, enteroendocrine and intestinal epithelial cells. ${ }^{33}$ Activation of $G$ proteincoupled receptors by SCFAs stimulates the production of glucagon-like peptide-1 (GLP-1) and the intestinal peptide YY (PYY). ${ }^{35}$ GLP-1 and PYY are both secreted from the enteroendocrine L-cells, predominantly distributed in the ileum and colon. ${ }^{36}$ GLP-1 regulates glucose, lipid and energy metabolism by binding to GLP-1 receptor, including stimulating glucose-dependent insulin secretion from pancreatic $\beta$ cells, reducing glucagon secretion from pancreatic $\alpha$ cells, $^{37}$ inhibiting the production of lipid proteins, ${ }^{38}$ slowing down gastric emptying, ${ }^{39}$ increasing energy expenditure and losing body weight. ${ }^{40}$ PYY participates in suppressing appetite and slowing gastric emptying. ${ }^{41}$ Butyrate, the main energy source of the colonic epithelium cell, can protect intestinal barrier through increasing tight junction protein expression (such as ZO-1 and occludin) and reducing intestinal permeability. ${ }^{42}$

\section{Trimethylamine-N-Oxide (TMAO)}

High consumption of meats contributes to undesirable health outcomes through the choline/carnitine-TMAOpathway (Figure 1C). Choline, which is a water-soluble nutrient, is essential for a wide range of biological activities. Evidences suggest that gut microbiota can convert beneficial dietary choline into the production that are detrimental to human health. ${ }^{43}$ Choline is metabolized to produce a precursor trimethylamine (TMA) by gut microbiota, primarily the Firmicutes and Proteobacteria phyla. $^{44}$ TMA is a gas that readily passes the intestinal wall. After being absorbed, TMA is oxidized to form TMAO by flavin monooxygenase 3 (FMO3) in live. ${ }^{45}$ Choline may escape microbial degradation and be converted into betaine and further metabolites (eg, dimethylglycine (DMG)) which have detrimental osmotic effects by mammalian mitochondrial pathways in kidney. ${ }^{46}$ High circulating level of TMAO can promote insulin resistance by forming N-Nitroso compounds and is a potent novel risk factor of $\mathrm{T}_{2} \mathrm{DM}{ }^{47}$ In addition, elevated circulating TMAO level independently predicts an increased risk of cardiovascular disease in clinical study. ${ }^{48-50}$ A study showed that TMAO could inhibit hepatic bile acid synthesis via activating the nuclear farnesoid $\mathrm{X}$ receptors (FXR) and small heterodimer partner (SHP) to accelerate aortic lesion formation in apoE ${ }^{-/-}$mice. ${ }^{51}$ Another study showed that TMAO induced oxidative stress, inflammation and endothelial dysfunction via activating ROS-TXNIPNLRP3 inflammasome in human umbilical vein endothelial cells, which was involved in development of atherosclerosis. $^{52}$ Furthermore, another study suggested that TMAO may induce synaptic plasticity deficits by promoting endoplasmic reticulum stress-mediated PERK signaling pathway. ${ }^{53}$ TMAO may be identified a potential new therapeutic target for diabetes and other metabolic disorders.

\section{Bile Acids (BAs)}

BAs, as one of the gut microbiota producing metabolites, also participate in lipid and glucose metabolism and are directly or indirectly related to insulin resistance (Figure 1D). ${ }^{54}$ Cumulative data demonstrate that manipulation of BAs via regulating the composition of gut microbiota could help glycemic control and prevent metabolic memory for early-onset T2DM subjects. ${ }^{55}$ Primary bile acids (eg, chenodeoxycholic acid (CDCA) and cholic acid (CA)) are synthesized from cholesterol in hepatocytes and stored in the gallbladder. After a meal, bile acids are excreted into the duodenum to facilitate the absorption of dietary lipids. After they complete their job, most bile acids (more than 95\%) are efficiently reabsorbed in terminal ileum and recirculated to the liver via enterohepatic circulation. The remaining 5\% are excreted via feces. ${ }^{56}$ Secondary bile acids (eg, deoxycholic acid (DCA), lithocholic acid (LCA), and ursodeoxycholic acid (UDCA)) are derived from primary bile acids, mainly by the biosynthesis of few gut microbes. Both primary bile acids and their respective secondary bile acids act as key pleiotropic signaling mediators in glucose metabolism through activating FXR and/or the membrane Takeda G-protein-coupled receptor 5 (TGR5). ${ }^{57}$ FXR is abundantly expressed in liver and intestine. ${ }^{58}$ The relative binding affinity of primary and secondary bile acids to FXR is variable $(\mathrm{CDCA}>\mathrm{DCA}>\mathrm{LCA}>\mathrm{CA}>$ UDCA). ${ }^{59,60}$ TGR5 is highly expressed in liver, gastrointestinal tract, immune cells, gallbladder and pancreas. ${ }^{61}$ Like FXR, its relative binding affinity to primary and secondary bile acids varies substantially (LCA $>$ DCA $>$ CDCA $>$ CA $>$ UDCA). ${ }^{59}$ Changes of FXR and/or TGR5 regulate the expression of GLP-1 and PYY, hepatic gluconeogenesis, glycogen synthesis and energy expenditure. FXR deficiency increases the secretion of GLP-1 to improve glucose metabolism. ${ }^{60}$ Activation of TGR5 potently stimulates GLP-1 ${ }^{62}$ and $P Y^{63}$ secretion. 


\section{Impact of Anti-Hyperglycemic Agents on the Gut Microbiome Composition}

Owing to the importance of gut microbiome in T2DM, we discuss the interaction between gut microbiome and antihyperglycemic agents and how do they take effect.

\section{Metformin}

Metformin has been the first-line medication for T2DM more than 60 years worldwide. Metformin can effectively control hyperglycemia through decreasing hepatic gluconeogenesis, reducing hepatic glucose output, and increasing glucose uptake and utilization in muscle cells and adipocytes. ${ }^{64}$ Metformin is usually administered through orally. The oral bioavailability is about $30-60 \%$, and up to $30 \%$ of an ingested dose is eliminated through the feces. ${ }^{65}$ As a result, multiple evidences suggest that the anti-diabetic effect of metformin is at least partly mediated by gut microbiota. ${ }^{66}$ In a study of HFD-induced obese mice, when treated with metformin, the abundance of Akkermansia muciniphila $(12.44 \% \pm 5.26 \%)$ and Clostridium cocleatum $(0.10 \%$ $\pm 0.09 \%$ ) was significantly increased in the mice. ${ }^{67} \mathrm{An}$ exploratory longitudinal study in healthy volunteers of Latvian was performed to observe the short-term effects of metformin on the gut microbiome. ${ }^{68}$ Participants were treated with metformin $850 \mathrm{mg}$ twice daily for 7 days. After metformin administration, the inner diversity of gut microbiota was significantly reduced. Meanwhile, the families Peptostreptococcaceae (M24h vs M7d $=0.72 \%$ vs $0.18 \%$ ) and Clostridiaceae_1 (M24h vs M7d $=0.49 \%$ vs $0.10 \%$ ) and four genera within these families were significantly decreased. In another study in healthy young Danish men, the participants were given metformin up to $1 \mathrm{~g}$ twice daily. ${ }^{69}$ The abundance of Intestinibacter spp. and Clostridium spp. was reduced, while the abundance of Escherichia/Shigella spp. and Bilophila wadsworthia was increased. After discontinuation of metformin, these changes were reversed. This study also demonstrated that the relative abundance at baseline of 12 bacterial genera could predict the risk of gastrointestinal adverse effects of metformin.

The effects of metformin in newly diagnosed T2DM patients were different from healthy individuals. ${ }^{70}$ The alpha diversity of microbiota was reduced after metformin treatment, but not in T2DM. At the species level, the abundance of Clostridium bartlettii and Barnesiella intestinihominis was reduced, while the abundance of Parabacteroides distasonis and Oscillibacter was increased. Baseline gut microbiome composition predicted the different efficacy of metformin therapy (changes in HbAlc level) and the incidence of side effects. Another study of patients with T2DM in Japan, the ratio of Firmicutes/ Bacteroidetes was significantly decreased (before: $2.72 \pm 1.45$; after four weeks: $2.26 \pm 1.09 ; p=$ 0.04) after four weeks of metformin treatment. ${ }^{71}$ The decrease of the genus Parabacteroides was associated with abdominal pain $(\mathrm{r}=-0.56, p=0.008)$. The decrease of Parabacteroides $(\mathrm{r}=-0.53, p=0.01)$ and Bifidobacterium ( $\mathrm{r}=-0.56, p=0.008)$ might be a predictor of abdominal pain and reflux.

Accumulating evidences suggested that metformin improved glucose homeostasis by several underlying mechanism in diabetes. A study in Colombian found that metformin helped ameliorating hyperglycemia and was positively associated with the abundance of SCFAproducing bacteria, including Akkermansia muciniphila, Butyrivibrio, Bifidobacterium bifidum, Megasphaera, and an operational taxonomic unit of Prevotella. ${ }^{72}$ In $\mathrm{db} / \mathrm{db}$ mice, metformin treatment had been shown to inhibit bacterial TMA production and decrease TMAO availability. ${ }^{73}$ The effect of metformin on glucose metabolism was also linked to bile acid metabolism. ${ }^{74}$ In the individuals with newly diagnosed T2DM, metformin treatment could decrease Bacteroides fragilis and increase the bile acid glycoursodeoxycholic acid (GUDCA) via inhibiting intestinal FXR signaling, thereby improving glucose metabolism. ${ }^{75}$ However, the gut microbiota composition after metformin treatment may differ from these results due to different species, individuals and experimental design.

All above, we concluded that metformin exerted the glucose-lowering effect at least partly through affecting microbiome composition, and an individual's tolerance or intolerance to metformin may also be influenced by the baseline composition of gut microbiome. ${ }^{65}$ Firstly, Forslund et al found that the increased abundance of Escherichia was consistent with well-known gastrointestinal side effects of metformin treatment. ${ }^{76}$ Secondly, in healthy volunteers of Latvian, an increased initial presence of gut opportunistic pathogen Escherichia-Shigella spp. before metformin administration was associated with the severity of gastrointestinal side effects. ${ }^{68}$ Lastly, another study in healthy young Danish men also indicated that the relative abundance at baseline of 12 bacterial genera might be a determinant for predicting gastrointestinal adverse effects following metformin intake. ${ }^{69}$ 


\section{$\alpha$-Glucosidase Inhibitor}

The $\alpha$-glucosidase inhibitors, including acarbose, voglibose and miglitol, are commonly used oral hypoglycemic agents in Asian, since their diet contains high content of carbohydrates. Under normal condition, the carbohydrates are digested and absorbed in the small intestine. The administration of $\alpha$-glucosidase inhibitors specifically inhibite the $\alpha$-glucosidase in the brush border of the small intestine, resulting in a delay of the absorption of carbohydrates in the small intestine and reduction of postprandial glucose concentration. ${ }^{77}$ When passing through the colon, the undigested carbohydrates are fermented by gut bacteria, and the microbial ecosystem changes to some degree. ${ }^{78}$ There are diverse influences on the abundance of gut microbiota after different glycosidase inhibitors. ${ }^{79}$

In mice fed with either a high-starch or high-fiber diet, acarbose treatment changed gut community, including an increase of the Bacteroidaceae and Bifidobacteriaceae and a decrease of the Verrucomicrobiaceae (such as Akkermansia muciniphila) and the Bacteroidales S24-7, but not irreversibly. ${ }^{80}$ These changes resulted in an increase of beneficial SCFA, especially butyrate. A recent human study of prediabetic patients also found that acarbose increased the abundance of SCFA-producing taxa, such as Faecalibacterium, Prevotella, and Lactobacillus. $^{81}$ Acarbose treatment maybe increased median lifespan through increasing fecal SCFA concentrations in mice. ${ }^{78}$ In another cohort of Chinese patients with T2DM, the Bifidobacterium longum $(8.49 \pm 1.00$ vs 7.92 \pm 1.18 lgcopies $/ g, P=0.005$ ) and Enterococcus faecalis (6.61 \pm 1.27 vs $8.08 \pm 1.20$ lgcopies/g, $P=0.001)$ were significantly increased after 4 weeks of acarbose treatment. ${ }^{82}$ These changes of gut microbiota were negatively correlated with inflammatory cytokines, including LPS, PAI-1 and MCP-1. Acarbose treatment also altered the composition of gut microbiome and bile acid profiles, resulting in the improvement of glucose metabolism. ${ }^{83}$

\section{Thiazolidinediones (TZDs)}

Thiazolidinediones (TZDs), also termed as selective peroxisome proliferator-activated receptor- $\gamma$ (PPAR)- $\gamma$ agonists, are potent oral insulin sensitizers used for T2DM treatment. ${ }^{84}$ This class of drugs once fell into disuse because of serious side effects. Thiazolidinediones reduce hepatic glucose production and increase peripheral utilization of glucose and lipid metabolism by increasing the transactivation activity of PPARs, resulting in improved glycemic control. ${ }^{85}$ PPAR- $\gamma$ is predominantly expressed at high levels in adipose tissue, and is also abundantly expressed in colonic epithelial cells. ${ }^{86}$ Thiazolidinediones may influence gut microbiota.

In diabetic $\mathrm{db} / \mathrm{db}$ mice, rosiglitazone treatment significantly improved insulin sensitivity and glucose homeostasis without altering gut bacterial composition. ${ }^{87} \mathrm{~A}$ global gene expression analysis in rosiglitazone-treated $\mathrm{db} / \mathrm{db}$ mice showed substantial changes in colon and ileum, with no change in duodenum. Rosiglitazone treatment stimulated fatty acid metabolism by regulating the gene markers of intestinal fatty uptake, transport and disposal in the colon and ileum. The genes involved in gluconeogenesis were upregulated in colon, while the genes involved in glycolysis were downregulated in cecum and ileal. These effects were consistent with the fact that PPAR- $\gamma$ being abundantly expressed in colonic epithelial cells. ${ }^{87}$ Another study found that Danshensu Bingpian Zhi (DBZ), a unique PPAR- $\gamma$ partial agonist, prevented HFD-induced obesity and insulin resistance through modulating gut microbiota dysbiosis. ${ }^{88}$ DBZ treatment restored intestinal barrier integrity and reversed gut dysbiosis by increasing the ratio of Bacteroidetes to Firmicutes, the relative abundance of Akkermansia, and reducing the level of HFD-induced pernicious bacteria (such as Helicobacter marmotae, Odoribacter, and Anaerotruncus). DBZ was effective for metabolic syndrome without side effects, which is a promising approach novel therapeutic agent for metabolic diseases. The gut microbiota composition of girls with polycystic ovary syndrome (PCOS) was different from those in healthy controls, including a reduction of alpha diversity, a reduction of Prevotellaceae, Prevotella and Senegalimassilia and an increase of Bacillales Family $X I{ }^{89}$ Spironolactone-pioglitazone-metformin (SPIOMET) treatment normalized the abundance of Family XI.

\section{Glucagon-Like Peptide-I (GLP-I) Receptor Agonist and Dipeptidyl Peptidase-4 (DPP-4) Inhibitors}

GLP-1, an incretin hormone secreted by enteroendocrine $\mathrm{L}$ cells in the distal ileum and colon, can stimulate glucose-dependent insulin secretion and suppress glucagon secretion. ${ }^{90}$ GLP-1 is degraded within $2 \sim 3$ mins in the circulation via enzymatic inactivation by DPP-4. ${ }^{90}$ At present, various GLP-1 receptor agonists (GLP-1RAs) and DPP-4 inhibitors (DPP-4i) have been developed and widely used in T2DM treatment. ${ }^{91}$ GLP-1RAs include 
the short-acting compounds (exenatide and lixisenatide) and the long-acting compounds (liraglutide, dulaglutide, albiglutide). The short-acting GLP-1RAs, which are resistant to the cleavage by DPP4, primarily lower postprandial blood glucose level through substantial retardation of gastric emptying. While the long-acting GLP-1RAs, binding to plasma albumin, have a stronger effect on fasting glucose level through their insulinotropic and glucagonostatic actions. ${ }^{92}$ Besides the glucose-lowering effect, GLP-1 can inhibit appetite and delay gastric emptying to reduce food intake. Therefore, GLP-1RAs are also recognized as a promising anti-obesity agent in simple obesity and diabetic obesity. However, recent studies indicated that GLP1 had more beneficial effect on weight loss and glucose metabolism by modulating gut microbial composition than that by restricting food intake alone. ${ }^{93-95}$ A study provided evidence that in both simple obese and diabetic obese rats, liraglutide, as a GLP-1 analog, was able to attenuate blood glucose levels and suppress body weight gain via changing the structure of gut microbiota, including decreasing microflora community richness and diversity, increasing Bacteroidetes and decreasing Firmicutes phyla, decreasing the obesity-related phylotypes and increasing the leanrelated phylotypes. ${ }^{93}$ Liraglutide effectively prevented the development of diabetes in rats through elevating SCFAproducing bacteria, including Bacteroides, Lachnospiraceae, and probiotic bacteria, Bifidobacterium. $^{94}$ In patients with T2DM, liraglutide could reduce gut microbial alpha diversity and alter gut microbiota composition, including increasing Firmicutes and Bacteroidetes and reducing Ruminococcus (Firmicutes) and Actinomyces (Actinobacteria). ${ }^{95}$ Another study confirmed liraglutide was also associated with attenuating nonalcoholic fatty liver disease (NAFLD) through changing the structure of gut microbiota. ${ }^{96,97}$ Liraglutide could reduce the genus of Proteobacteria and increase the genus of Akkermansia muciniphila in HFDfed mice. ${ }^{97}$ A recent research found that GLP-1/GLP-2 coagonists, GUB09-145, had more effect on reducing food intake and improving glucose tolerance than GLP-1 receptor agonist. ${ }^{98}$ The biological actions of GLP-1 and GLP-2 receptor signaling on caloric intake and glucose metabolism in diet-induced obese mice were associated with gut bacterial compositional changes. ${ }^{99}$

DPP4i exerts glucose-lowering effect through inhibiting DPP4 activity and raising the plasma level of native GLP-1. ${ }^{100}$ In T2DM patients, treatment with sitagliptin, a DPP-4i, obviously increased the abundance of
Bacteroidetes, especially the production of succinate. ${ }^{101}$ In this study, fecal microbiota transplantation (FMT) was further performed in germ-free mice to confirm the effect of sitagliptin on gut microbiota. These results indicated that the hypoglycemic effect of DPP-4i was at least partially mediated by the alterations of gut microbiota. An animal study found that sitagliptin treatment exerted beneficial effects on gut microbiota, especially increasing SCFA-producing bacteria, Blautia, Roseburia, and Clostridium, and probiotics Lactobacillus, Bifidobacterium. ${ }^{102}$ Another study in Western diet-fed mice, vildagliptin exerted beneficial effects by modulating of gut microbiota and increasing the amount of propionate, thus ameliorating gastrointestinal health. But there were no differences in total amount of SCFA, acetate or butyrate. $^{103}$

\section{Sodium Glucose Co-Transporter 2 Inhibitors (SGLT2i)}

Sodium glucose co-transporter 2 (SGLT2) is expressed in the renal proximal tubule and accounts for reabsorbing approximately $90 \%$ of filtered glucose, whereas sodium glucose co-transporter 1 (SGLT1) is predominantly expressed in the small intestine mucosa and accounts for transporting glucose into intestinal enterocytes. ${ }^{104}$ SGLT2 inhibitors are oral anti-hyperglycemic medications for T2DM treatment, which can effectively improve glycemic control by blocking glucose reabsorption in the renal proximal tubule and increasing urinary glucose excretion. $^{105}$ Even though the affinity to SGLT2 of SGLT2 inhibitors is significantly greater than SGLT1, SGLT2 inhibitors also have some affinity for SGLT1. Considering this, SGLT2 inhibitors potentially influence gut microbiota composition through reducing intestinal glucose uptake. ${ }^{106}$ Thus far, there are a few researches about the effects of SGLT2 inhibitors or SGLT1/2 dual inhibitors on gut microbiome composition, but the results are controversial. Early study found that dapagliflozin, a SGLT2 inhibitor, improved vascular dysfunction concomitantly subtly altering microbiota diversity in T2DM db/ db mice. ${ }^{107}$ Dapagliflozin treatment could increase the abundance of beneficial bacterial species Akkermansia muciniphila and reduce Firmicutes/Bacteroidetes. ${ }^{107}$ However, whether these alterations of microbiota conclusively mediate the improvement on vascular function need to be further studied. Further preclinical studies about the effect of SGLT2 inhibitors on type 1 diabetes mellitus 
(T1DM) are currently underway. After dapagliflozin or empagliflozin treatment, the intermediate metabolite of gut metabolism known as succinate was significantly reduced in type 1 diabetic mice with diabetic retinopathy. ${ }^{108}$ Succinate was reported to promote the angiogenic factor VEGF expression in retinal ganglion cells and was shown to be a pathogenic factor in diabetic retinopathy. ${ }^{109}$ Another study in patients with T2DM, dapagliflozin treatment as add-on to metformin therapy had no effect on gut microbiome composition. ${ }^{110}$ The dosages of metformin were equal among intervention participants, but the effects of metformin on microbiome composition were very potent. Maybe metformin overshadowed the potential effect of dapagliflozin on microbiome composition. Unlike people, mice are cohousing animals. Then, it also may be a confounding factor. Above all, the effect of SGLT2 inhibitors on microbiome composition was slight. Potent SGLT1/2 dual inhibitor, which can reduce glucose uptake and increase urinary glucose excretion, was more powerful than SGLT2 inhibitor in lowering blood glucose. ${ }^{111}$ However, SGLT1/2 inhibitor alone did not alter gut microbiota composition in mice. If increasing glucose by high sucrose diet, SGLT1/2 inhibitor would alter the relative abundance of certain phyla to a certain extent. ${ }^{112}$

\section{Traditional Chinese Medicine}

Traditional Chinese medicine, which had recorded knowledge for more than 2000 years, could significantly improve glucose control and clinical indices through different molecular mechanisms, including simulating insulin secretion, enhancing insulin sensitivity and protecting $\beta$ cells. ${ }^{113}$ Accumulating evidences recently confirmed that traditional Chinese medicine alleviated diabetes at least partly by modulating the structure of the gut microbiota. ${ }^{114}$

Recently, studies indicated that polysaccharides from natural resources exerted beneficial effect on glucose metabolism. Polysaccharides, as macromolecular carbohydrates, are indigestible and fermentative in the intestinal tract after oral administration. So, polysaccharides would regulate gut microflora composition to alleviate diabetes. Holothuria leucospilota, as an edible tropical sea cucumber species, could improve glucose metabolism by regulating the structure of the gut microbiota on diabetic GK rats, including increasing the abundance of beneficial bacteria (such as Bacteroidetes, TM7, Cyanobacteria and Tenericutes) and SCFA-producing species of gut microbiota (such as Clostridium, Turicibacter, Allobaculum and Ruminococcus) and decreasing the conditional pathogenic bacteria (such as Anaerobiospirillum, Collinsella and Treponema). ${ }^{115}$ Pumpkin polysaccharide also could enrich key species of Bacteroidetes, Prevotella, Deltaproteobacteria, Oscillospira, Veillonellaceae, Phascolarctobacterium, Sutterella and Bilophila, leading to an increase of SCFA production in diabetic rats. ${ }^{116}$ Sargassum fusiforme fucoidan treatment alleviated streptozotocin-induced hyperglycemia in mice by increasing the relative abundances of SCFAs-producing bacteria, such as Bilophila, Oscillibacter, Mucispirillum, especially Alloprevotella. ${ }^{117}$ Mulberry fruit polysaccharides could efficiently alleviate hyperglycemia, dyslipidemia and oxidative stress partly by modulating gut microbiota. ${ }^{118}$ Mulberry fruit polysaccharides strongly increased the abundance of Akkermansia, resulting in the reduce of insulin resistance. ${ }^{118}$ In diabetic mice, polysaccharides from adlay seed increased the abundance of Lactobacillus spp. and Lactobacillus fermentum in diabetic mice, which may be associated with their beneficial role in T2DM. Furthermore, polysaccharides from adlay seed significantly increased the concentration of GLP-1 and reduced antiamyloid beta (A $\beta 1-42)$ protein. ${ }^{119}$ Furthermore, long-term polysaccharides intake also have preventive and therapeutic effect on obesity $^{120}$ and TMAO-induced cardiac dysfunction ${ }^{121}$ by targeting gut microbiota. In HFD-induced obese rats, a mixture of lentinan and Flos Lonicera polysaccharide (LF) could reduce TMAO in the urine, suggesting that LF could have a potential role in reducing the risk of atherosclerosis. ${ }^{120}$ Ganoderma lucidum spore (GS) polysaccharides could alleviate TMAO-induced cardiac dysfunction in rats by targeting gut microbiota, such as increasing the abundance of Firmicutes and Proteobacteria and reducing the abundance of Actinobacteria and Tenericutes. ${ }^{121}$ The flavonoids in Scutellaria baicalensis and the alkaloids in Coptis chinensis are a classic herbal pair for ameliorating diabetes and various intestinal diseases by inhibiting inflammation and modulating gut microbiota. Zhang et al initially found that Scutellaria-coptis exhibited the effect of relieving insulin resistant by regulating intestinal flora and inhibiting inflammatory reaction. ${ }^{122}$ Moreover, it was demonstrated that Scutellaria-coptis obviously improved metabolic disorders by increasing SCFAs-producing bacteria and decreasing secondary BAs-producing bacteria. ${ }^{123}$ Furthermore, the hypoglycaemic effects of Scutellaria-Coptis were involved in regulating gut microbiota and alleviating intestinal mucosal barrier damage. ${ }^{124}$ Scutellaria-Coptis significantly inhibited some potential enteropathogenic bacteria and LPS-producing bacteria, such as Proteobacteria, Enterobacteriaceae, Enterobacter, Escherichia-Shigella, and Enterococcus, and 
Table I The Interaction Between Anti-Hyperglycemic Agents, Traditional Chinese Medicine and Specific Gut Microbiota Composition Changes

\begin{tabular}{|c|c|c|c|c|c|}
\hline \multirow{2}{*}{$\begin{array}{l}\text { Glucose- } \\
\text { Lowering } \\
\text { Agent }\end{array}$} & \multirow[t]{2}{*}{ Treatment } & \multirow{2}{*}{$\begin{array}{l}\text { Research } \\
\text { Subjects }\end{array}$} & \multicolumn{2}{|c|}{ The Change of Gut Microbiota } & \multirow[t]{2}{*}{ References } \\
\hline & & & Increased Abundance & Decreased Abundance & \\
\hline \multirow[t]{6}{*}{ Metformin } & $\begin{array}{c}300 \mathrm{mg} / \mathrm{kg} \text { every day for } \\
10 \text { weeks }\end{array}$ & $\begin{array}{l}\text { Mouse model of } \\
\text { HFD-induced } \\
\text { obesity }\end{array}$ & $\begin{array}{l}\text { Akkermansia muciniphila; Clostridium } \\
\text { cocleatum }\end{array}$ & & {$[67]$} \\
\hline & $\begin{array}{c}850 \mathrm{mg} \text { twice daily for } 7 \\
\text { days }\end{array}$ & $\begin{array}{l}\text { Healthy } \\
\text { volunteers of } \\
\text { Latvian }\end{array}$ & & $\begin{array}{c}\text { The families } \\
\text { Peptostreptococcaceae and } \\
\text { Clostridiaceae_l }\end{array}$ & [68] \\
\hline & I g twice daily for 6 weeks & $\begin{array}{l}\text { Healthy young } \\
\text { Danish men }\end{array}$ & $\begin{array}{l}\text { Escherichia/Shigella spp. and Bilophila } \\
\text { wadsworthia }\end{array}$ & $\begin{array}{l}\text { Intestinibacter spp. and } \\
\text { Clostridium spp. }\end{array}$ & [69] \\
\hline & $\begin{array}{c}850 \text { mg twice daily for } 7 \\
\text { days }\end{array}$ & $\begin{array}{l}\text { Newly diagnosed } \\
\text { T2DM patients }\end{array}$ & Parabacteroides distasonis and Oscillibacter & $\begin{array}{l}\text { Clostridium bartlettii and } \\
\text { Barnesiella intestinihominis }\end{array}$ & [70] \\
\hline & $\begin{array}{c}500 \mathrm{mg} \text { per day for } 2 \\
\text { weeks and then } 1000 \mathrm{mg} \\
\text { per day for } 2 \text { weeks }\end{array}$ & $\begin{array}{l}\text { Japanese patients } \\
\text { with T2DM }\end{array}$ & & $\begin{array}{l}\text { The ratio of Firmicutes/ } \\
\text { Bacteroidetes; Parabacteroides } \\
\text { and Bifidobacterium }\end{array}$ & [7I] \\
\hline & & $\begin{array}{l}\text { Colombian adults } \\
\text { with or without } \\
\text { diabetes }\end{array}$ & $\begin{array}{l}\text { The abundance of SCFA-producing bacteria, } \\
\text { including Akkermansia muciniphila, Butyrivibrio, } \\
\text { Bifidobacterium bifidum, Megasphaera, and an } \\
\text { operational taxonomic unit of Prevotella. }\end{array}$ & & [72] \\
\hline \multirow[t]{3}{*}{ Acarbose } & $\begin{array}{c}25 \mathrm{mg} / \mathrm{kg} \text { or } 400 \mathrm{mg} / \mathrm{kg} \text { for } \\
2 \text { weeks }\end{array}$ & $\begin{array}{l}\text { In mice fed either } \\
\text { a high-starch or } \\
\text { high-fiber diet }\end{array}$ & Bacteroidaceae and Bifidobacteriaceae & $\begin{array}{c}\text { The Verrucomicrobiaceae (such } \\
\text { as Akkermansia muciniphila) and } \\
\text { the Bacteroidales S24-7 }\end{array}$ & {$[80]$} \\
\hline & $\begin{array}{l}50 \mathrm{mg} \text { once daily on days } \\
\mathrm{I}-3,50 \mathrm{mg} \text { twice daily on } \\
\text { days } 4-7,50 \mathrm{mg} \text { three } \\
\text { times daily for } 4 \text { weeks }\end{array}$ & $\begin{array}{l}\text { Prediabetic } \\
\text { patients }\end{array}$ & $\begin{array}{l}\text { The abundance of SCFA-producing taxa, such } \\
\text { as Faecalibacterium, Prevotella, and Lactobacillus }\end{array}$ & & {$[81]$} \\
\hline & $150 \mathrm{mg} /$ day for 4 weeks & $\begin{array}{l}\text { Chinese patients } \\
\text { with T2DM }\end{array}$ & $\begin{array}{l}\text { Bifidobacterium longum and Enterococcus } \\
\text { faecalis }\end{array}$ & & {$[82]$} \\
\hline $\begin{array}{l}\text { Danshensu } \\
\text { Bingpian Zhi } \\
\text { (DBZ) }\end{array}$ & $\begin{array}{c}50 \mathrm{mg} / \mathrm{kg} \text { or } 100 \mathrm{mg} / \mathrm{kg} \text { for } \\
10 \text { weeks }\end{array}$ & HFD-fed mice & $\begin{array}{l}\text { Bacteroidetes/Firmicutes ratio; the relative } \\
\text { abundance of Akkermansia }\end{array}$ & $\begin{array}{l}\text { Helicobacter marmotae, } \\
\text { Odoribacter, Anaerotruncus }\end{array}$ & [88] \\
\hline \multirow[t]{4}{*}{ Liraglutide } & $\begin{array}{c}400 \mu \mathrm{g} / \mathrm{kg} / \text { day for } 12 \\
\text { weeks }\end{array}$ & $\begin{array}{l}\text { Both simple } \\
\text { obese and } \\
\text { diabetic obese } \\
\text { rats }\end{array}$ & $\begin{array}{l}\text { Bacteroidetes phyla; the lean-related } \\
\text { phylotypes }\end{array}$ & $\begin{array}{l}\text { Firmicutes phyla; the obesity- } \\
\text { related phylotypes }\end{array}$ & [93] \\
\hline & $\begin{array}{l}0.2 \mathrm{mg} / \mathrm{kg} / \text { day or } 0.4 \mathrm{mg} / \\
\mathrm{kg} / \text { day for } 12 \text { weeks }\end{array}$ & $\begin{array}{l}\text { Diabetic rat } \\
\text { model }\end{array}$ & $\begin{array}{c}\text { SCFA-producing bacteria (Bacteroides, } \\
\text { Lachnospiraceae, probiotic bacteria, } \\
\text { Bifidobacterium) }\end{array}$ & & [94] \\
\hline & $\begin{array}{l}1.2 \mathrm{mg} \text { once daily for } 4 \\
\text { months }\end{array}$ & $\begin{array}{l}\text { Patients with } \\
\text { T2DM }\end{array}$ & Firmicutes and Bacteroidetes & $\begin{array}{l}\text { Ruminococcus (Firmicutes) and } \\
\text { Actinomyces (Actinobacteria) }\end{array}$ & [95] \\
\hline & $\begin{array}{c}200 \mu \mathrm{g} / \mathrm{kg} \text { twice daily for } \\
15 \text { days }\end{array}$ & $\begin{array}{l}\text { HFD induced } \\
\text { obese mice and } \\
\text { the genetically } \\
\text { obese mice, ob/ } \\
\text { ob mice }\end{array}$ & The genus of Akkermansia muciniphila & The genus of Proteobacteria & [97] \\
\hline
\end{tabular}


Table I (Continued).

\begin{tabular}{|c|c|c|c|c|c|}
\hline \multirow{2}{*}{$\begin{array}{l}\text { Glucose- } \\
\text { Lowering } \\
\text { Agent }\end{array}$} & \multirow[t]{2}{*}{ Treatment } & \multirow{2}{*}{$\begin{array}{l}\text { Research } \\
\text { Subjects }\end{array}$} & \multicolumn{2}{|c|}{ The Change of Gut Microbiota } & \multirow[t]{2}{*}{ References } \\
\hline & & & Increased Abundance & Decreased Abundance & \\
\hline \multirow[t]{2}{*}{ Sitagliptin } & $100 \mathrm{mg} / \mathrm{d}$ for 2 months & T2DM patients & $\begin{array}{l}\text { The abundance of Bacteroidetes; the } \\
\text { production of succinate. }\end{array}$ & & {$[101]$} \\
\hline & $\begin{array}{l}10 \mathrm{mg} / \mathrm{kg} \text { once a day for } \\
12 \text { weeks }\end{array}$ & $\begin{array}{l}\text { A streptozotocin } \\
\text { treated high fat/ } \\
\text { high carbohydrate } \\
\text { fed rat model }\end{array}$ & $\begin{array}{l}\text { The abundance of Firmicutes and } \\
\text { Tenericutes; SCFA-producing bacteria, } \\
\text { Blautia, Roseburia, and Clostridium, and } \\
\text { probiotics Lactobacillus, Bifidobacterium }\end{array}$ & $\begin{array}{l}\text { The abundance of } \\
\text { Bacteroidetes }\end{array}$ & {$[102]$} \\
\hline Dapagliflozin & $\begin{array}{c}60 \mathrm{mg} \text { dapagliflozin } / \mathrm{kg} \\
\text { diet; } 0.006 \%) \text { for } 8 \text { weeks. }\end{array}$ & Diabetic mice & The abundance of Akkermansia muciniphila & Firmicutes/Bacteroidetes & {$[107]$} \\
\hline $\begin{array}{l}\text { Holothuria } \\
\text { leucospilota }\end{array}$ & $\begin{array}{l}100 \mathrm{mg} / \mathrm{kg} \text { or } 200 \mathrm{mg} / \mathrm{kg} \\
\text { for } 4 \text { weeks }\end{array}$ & Diabetic GK rats & $\begin{array}{l}\text { The abundance Bacteroidetes, TM7, } \\
\text { Cyanobacteria and Tenericutes; SCFA- } \\
\text { producing species (Clostridium, Turicibacter, } \\
\text { Allobaculum and Ruminococcus) }\end{array}$ & $\begin{array}{c}\text { Anaerobiospirillum, Collinsella, } \\
\text { Treponema }\end{array}$ & [115] \\
\hline $\begin{array}{l}\text { Pumpkin } \\
\text { polysaccharide }\end{array}$ & $\begin{array}{c}1000 \mathrm{mg} / \mathrm{kg} \text { once daily for } \\
4 \text { weeks }\end{array}$ & Diabetic rats & $\begin{array}{l}\text { Bacteroidetes, Prevotella, Deltaproteobacteria, } \\
\text { Oscillospira, Veillonellaceae, } \\
\text { Phascolarctobacterium, Sutterella and Bilophila }\end{array}$ & & [116] \\
\hline $\begin{array}{l}\text { Sargassum } \\
\text { fusiforme } \\
\text { fucoidan }\end{array}$ & $100 \mathrm{mg} / \mathrm{kg}$ for 6 weeks & $\begin{array}{l}\text { STZ-induced } \\
\text { diabetic mouse } \\
\text { model }\end{array}$ & $\begin{array}{l}\text { The abundances of SCFAs-producing } \\
\text { bacteria, such as Bilophila, Oscillibacter, } \\
\text { Mucispirillum, especially Alloprevotella }\end{array}$ & & {$[117]$} \\
\hline $\begin{array}{l}\text { Mulberry fruit } \\
\text { polysaccharides }\end{array}$ & $\begin{array}{l}200 \mathrm{mg} / \mathrm{kg} \text { or } 500 \mathrm{mg} / \mathrm{kg} \\
\text { or } 800 \mathrm{mg} / \mathrm{kg} \text { for } 8 \text { weeks }\end{array}$ & $\begin{array}{l}\text { Diabetic } \mathrm{db} / \mathrm{db} \\
\text { mice }\end{array}$ & The abundance of Akkermansia & & [1।8] \\
\hline $\begin{array}{l}\text { Polysaccharides } \\
\text { from adlay seed }\end{array}$ & $24 \mathrm{mg} / \mathrm{kg} /$ day for 4 weeks & Diabetic mice & $\begin{array}{l}\text { The abundance of Lactobacillus spp. and } \\
\text { Lactobacillus fermentum }\end{array}$ & & {$[119]$} \\
\hline \multirow[t]{2}{*}{ Scutellaria-coptis } & $6.3 \mathrm{~g} / \mathrm{kg}$ for I month & Diabetic rats & $\begin{array}{l}\text { The SCFAs-producing bacteria such as } \\
\text { Bacteroidales S24-7 group_norank, } \\
\text { [Eubacterium] nodatum group, Parasutterella, } \\
\text { Prevotellaceae UCG-00I, Ruminiclostridium, and } \\
\text { Ruminiclostridium } 9\end{array}$ & $\begin{array}{l}\text { Secondary bile acid-producing } \\
\text { bacteria such as Escherichia- } \\
\text { Shigella }\end{array}$ & [123] \\
\hline & $\begin{array}{c}8.4 \text { or } 4.2 \text { or } 2.1 \mathrm{~g} / \mathrm{kg} / \text { day } \\
\text { for } 12 \text { weeks }\end{array}$ & Diabetic rats & $\begin{array}{c}\text { The abundances of butyrate-producing } \\
\text { bacteria, such as Lachnospiraceae and } \\
\text { Prevotellaceae }\end{array}$ & $\begin{array}{l}\text { LPS-producing bacteria, such } \\
\text { as Proteobacteria, } \\
\text { Enterobacteriaceae, } \\
\text { Enterobacter, Escherichia- } \\
\text { Shigella, and Enterococcus }\end{array}$ & [124] \\
\hline \multirow[t]{2}{*}{ Berberine } & $0.5 \mathrm{~g} / \mathrm{L}$ for 14 weeks & $\begin{array}{l}\text { HFD-induced } \\
\text { atherosclerosis }\end{array}$ & The abundance of Akkermansia spp. & & [129] \\
\hline & $100 \mathrm{mg} / \mathrm{kg}$ for 8 weeks & HFD-fed rats & $\begin{array}{l}\text { SCFA-producing bacteria (Blautia and } \\
\text { Allobaculum) }\end{array}$ & & {$[134]$} \\
\hline
\end{tabular}

increased the abundances of butyrate-producing bacteria, such as Lachnospiraceae and Prevotellaceae. ${ }^{124}$ The change of gut microbiota resulted in alleviating intestinal mucosa barrier damage by preventing the leakage of LPS and increasing the intestinal tight junction proteins claudin-1, occluding and ZO-1 in diabetic rats. ${ }^{124}$ Their anti-inflammation effect of Scutellaria-coptis was involved in TLR signalling pathway, ${ }^{122}$ TLR-4/TRIF and TNFR-1/NF- $\kappa$ B signaling pathways. ${ }^{124}$ In a clinical study, the T2DM patients who had already been prescribed metformin and were allotted to additional Scutellaria baicalensis, significantly reduced the TNF- $\alpha$ expression and influenced gut microbiota, especially Lactobacillus and Akkermansia. ${ }^{125}$ Furthermore, both in vivo and in vitro experiments indicated that nobiletin effectively 
prevented TMAO-stimulated vascular inflammation via inhi-

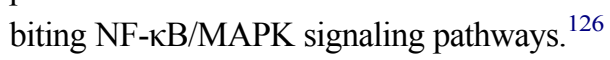

Berberine, an isoquinoline alkaloid extracted from Chinese traditional herb Coptis chinensis, was used to treat bacterial diarrhea in China for thousands of years. ${ }^{127}$ Berberine has poor oral bioavailability and leads to changes in the intestinal bacterial composition. Berberine exerts multiple beneficial effect against metabolic disease by modulating gut microbiota. ${ }^{128}$ Berberine significantly increased the abundance of Akkermansia spp., resulting in alleviating HFD-induced atherosclerosis. ${ }^{129}$ Furthermore, berberine could inhibit TMA/TMAO production by modulating gut microbiota composition. ${ }^{130}$ The anti-atherosclerotic effect of berberine may be partly attributed to the reduction of TMAO production. ${ }^{131}$ Berberine may be a better modulator to inhibit the development of atherosclerotic plaque. Recently, a large number of researches have demonstrated that berberine exhibited clinically beneficial effect in alleviating T2DM and could be possibly developed into a promising anti-diabetes candidate. ${ }^{132,133}$ Berberine administration enriched SCFA-producing bacteria, including Blautia and Allobaculum, and elevated fecal SCFA concentrations in HFD-fed rats, which may help to alleviate inflammation. ${ }^{134}$ Another study indicated that berberine inhibited LPS-induced TLR4/TNF- $\alpha$ activation. ${ }^{135}$ These findings suggested that berberine prevented insulin resistance at least partially attributable to structural modulation of the gut microbiota. Berberine could reduce TLR-4, NF$\mathrm{kB}$ and TNF-a expression, increase GLP-2 secretion and improve intestinal permeability by regulating gut microbiota in impaired glucose tolerance (IGT) rats, which may slow the progression of prediabetes to T2DM in ZDF rats. ${ }^{136}$ Berberine compounds could increase microbiome mediated deoxycholic acid (DCA) production and upregulate colonic TGR5 expression and GLP secretion in $d b / d b$ mice, which improved hyperglycemia. ${ }^{137}$ In China, a clinical trial in newly diagnosed T2DM patients found that the hypoglycaemic effect of berberine was associated with the inhibition of DCA biotransformation by Ruminococcus bromii and the reduction of the microbial production of secondary BA. ${ }^{138}$

\section{Conclusion and Future Perspectives}

So far, increasing researches have demonstrated that the alteration of gut microbiota composition and function played pivotal roles in the pathogenesis and treatment of T2DM. While animal and human studies in this field are limited in size. In this review, we summarized the effects of anti- hyperglycemic agents and traditional Chinese medicine on gut microbiota dysbiosis (summarized in Table 1). The potential gut-targeting glucose-lowering treatment strategies are now emerging, so further longitudinal and interventional studies in preclinical and clinical are needed to fully elucidate the potential mechanism of gut microbiota in T2DM and its potential use in the prevention and treatment of T2DM. We expect in-depth studies providing the basis for the development of novel antidiabetic drugs that target gut microbiota in the future. In conclusion, the modulation of gut microbiota is increasingly regarded as promising targets to improve glucose metabolism and treat T2DM. The development of novel drug presumably requires long and painstaking work with no scope for shortcuts.

\section{Acknowledgments}

This study was funded by Natural Science Foundation of Hebei Province (CN) 2020206108.

\section{Disclosure}

The authors declare no conflicts of interest.

\section{References}

1. Zheng Y, Ley SH, Hu FB. Global aetiology and epidemiology of type 2 diabetes mellitus and its complications. Nat Rev Endocrinol. 2018;14(2):88-98. doi:10.1038/nrendo.2017.151

2. Pascale A, Marchesi N, Marelli C, et al. Microbiota and metabolic diseases. Endocrine. 2018;61(3):357-371. doi:10.1007/s12020018-1605-5

3. Grice EA, Segre JA. The human microbiome: our second genome. Annu Rev Genomics Hum Genet. 2012;13:151-170. doi:10.1146/annurev-genom-090711-163814

4. Eckburg PB, Bik EM, Bernstein CN, et al. Diversity of the human intestinal microbial flora. Science. 2005;308(5728):1635-1638. doi:10.1126/science.1110591

5. Thursby E, Juge N. Introduction to the human gut microbiota. Biochem J. 2017;474(11):1823-1836. doi:10.1042/BCJ20160510

6. Tai N, Wong FS, Wen L. The role of gut microbiota in the development of type 1, type 2 diabetes mellitus and obesity. Rev Endocr Metab Disord. 2015;16(1):55-65. doi:10.1007/s11154015-9309-0

7. Kikuchi K, Saigusa D, Kanemitsu Y, et al. Gut microbiome-derived phenyl sulfate contributes to albuminuria in diabetic kidney disease. Nat Commun. 2019;10(1):1835. doi:10.1038/s41467-019-09735-4

8. Montandon SA, Jornayvaz FR. Effects of antidiabetic drugs on gut microbiota composition. Genes. 2017;8(10):250. doi:10.3390/ genes 8100250

9. Kyriachenko Y, Falalyeyeva T, Korotkyi O, Molochek N, Kobyliak N. Crosstalk between gut microbiota and antidiabetic drug action. World J Diabetes. 2019;10(3):154-168. doi:10.4239/ wjd.v10.i3.154

10. Zhang R, Gao X, Bai H, Ning K. Traditional Chinese medicine and gut microbiome: their respective and concert effects on healthcare. Front Pharmacol. 2020;11:538. doi:10.3389/ fphar.2020.00538 
11. Wang -R-R, Zhang L, Xu -J-J, et al. Human microbiome brings new insights to traditional Chinese medicine. J Bio-X Res. 2018;1 (1):41-44. doi:10.1097/JBR.0000000000000007

12. Zhong H, Ren H, Lu Y, et al. Distinct gut metagenomics and metaproteomics signatures in prediabetics and treatment-naïve type 2 diabetics. EBioMedicine. 2019;47:373-383. doi:10.1016/ j.ebiom.2019.08.048

13. Gao B, Zhong M, Shen Q, et al. Gut microbiota in early pregnancy among women with Hyperglycaemia vs. Normal blood glucose. BMC Pregnancy Childbirth. 2020;20(1):284. doi:10.1186/s12884-020-02961-5

14. Cao M, Peng Y, Lu Y, et al. Controls of hyperglycemia improves dysregulated microbiota in diabetic mice. Transplantation. 2021;105(9):1980-1988. doi:10.1097/TP.0000000000003603

15. Bouter KE, van Raalte DH, Groen AK, Nieuwdorp M. Role of the gut microbiome in the pathogenesis of obesity and obesity-related metabolic dysfunction. Gastroenterology. 2017;152 (7):1671-1678. doi:10.1053/j.gastro.2016.12.048

16. Fuke N, Nagata N, Suganuma H, Ota T. Regulation of gut microbiota and metabolic endotoxemia with dietary factors. Nutrients. 2019;11(10):2277. doi:10.3390/nu11102277

17. Gomes JMG, Costa JA, Alfenas RCG. Metabolic endotoxemia and diabetes mellitus: a systematic review. Metabolism. 2017;68:133-144. doi:10.1016/j.metabol.2016.12.009

18. Cani PD, Bibiloni R, Knauf $\mathrm{C}$, et al. Changes in gut microbiota control metabolic endotoxemia-induced inflammation in high-fat diet-induced obesity and diabetes in mice. Diabetes. 2008;57 (6):1470-1481. doi:10.2337/db07-1403

19. Allin KH, Nielsen T, Pedersen O. Mechanisms in endocrinology: gut microbiota in patients with type 2 diabetes mellitus. Eur $J$ Endocrinol. 2015;172(4):R167-177. doi:10.1530/EJE-14-0874

20. Gao J, Guo Z. Progress in the synthesis and biological evaluation of lipid A and its derivatives. Med Res Rev. 2018;38(2):556-601. doi:10.1002/med.21447

21. Cani PD, Osto M, Geurts L, Everard A. Involvement of gut microbiota in the development of low-grade inflammation and type 2 diabetes associated with obesity. Gut Microbes. 2012;3 (4):279-288. doi:10.4161/gmic. 19625

22. Saad MJ, Santos A, Prada PO. Linking gut microbiota and inflammation to obesity and insulin resistance. Physiology. 2016;31(4):283-293. doi:10.1152/physiol.00041.2015

23. Boulangé CL, Neves AL, Chilloux J, Nicholson JK, Dumas ME. Impact of the gut microbiota on inflammation, obesity, and metabolic disease. Genome Med. 2016;8(1):42. doi:10.1186/s13073016-0303-2

24. Alkanani AK, Hara N, Lien E, et al. Induction of diabetes in the RIP-B7.1 mouse model is critically dependent on TLR3 and MyD88 pathways and is associated with alterations in the intestinal microbiome. Diabetes. 2014;63(2):619-631. doi:10.2337/ db13-1007

25. Kim JJ, Sears DD. TLR4 and insulin resistance. Gastroenterol Res Pract. 2010;2010:212563.

26. Martens EC, Neumann M, Desai MS. Interactions of commensal and pathogenic microorganisms with the intestinal mucosal barrier. Nat Rev Microbiol. 2018;16(8):457-470. doi:10.1038/ s41579-018-0036-x

27. Tilg H, Zmora N, Adolph TE, Elinav E. The intestinal microbiota fuelling metabolic inflammation. Nat Rev Immunol. 2020;20 (1):40-54. doi:10.1038/s41577-019-0198-4

28. Thaiss CA, Levy M, Grosheva I, et al. Hyperglycemia drives intestinal barrier dysfunction and risk for enteric infection. Science. 2018;359(6382):1376-1383. doi:10.1126/science.aar3318

29. Maruta K, Takajo T, Akiba Y, et al. GLP-2 acutely prevents endotoxin-related increased intestinal paracellular permeability in rats. Dig Dis Sci. 2020;65(9):2605-2618. doi:10.1007/ s10620-020-06097-6
30. Cani PD, Possemiers S, Van de Wiele $\mathrm{T}$, et al. Changes in gut microbiota control inflammation in obese mice through a mechanism involving GLP-2-driven improvement of gut permeability. Gut. 2009;58(8):1091-1103. doi:10.1136/ gut.2008.165886

31. Cani PD. Crosstalk between the gut microbiota and the endocannabinoid system: impact on the gut barrier function and the adipose tissue. Clin Microbiol Infect. 2012;18(Suppl 4):50-53.

32. Heiss CN, Olofsson LE. Gut microbiota-dependent modulation of energy metabolism. $J$ Innate Immun. 2018;10(3):163-171. doi: $10.1159 / 000481519$

33. Priyadarshini M, Navarro G, Layden BT. Gut microbiota: FFAR reaching effects on islets. Endocrinology. 2018;159 (6):2495-2505. doi:10.1210/en.2018-00296

34. Yang Q, Ouyang J, Sun F, Yang J. Short-chain fatty acids: a soldier fighting against inflammation and protecting from tumorigenesis in people with diabetes. Front Immunol. 2020;11:590685. doi:10.3389/fimmu.2020.590685

35. Christiansen CB, Gabe MBN, Svendsen B, Dragsted LO, Rosenkilde MM, Holst JJ. The impact of short-chain fatty acids on GLP-1 and PYY secretion from the isolated perfused rat colon. Am J Physiol Gastrointest Liver Physiol. 2018;315(1):G53-g65. doi:10.1152/ajpgi.00346.2017

36. Xie C, Jones KL, Rayner CK, Wu T. Enteroendocrine hormone secretion and metabolic control: importance of the region of the gut stimulation. Pharmaceutics. 2020;12(9):790. doi:10.3390/ pharmaceutics 12090790

37. Hare KJ, Vilsbøll T, Asmar M, Deacon CF, Knop FK, Holst JJ. The glucagonostatic and insulinotropic effects of glucagon-like peptide 1 contribute equally to its glucose-lowering action. Diabetes. 2010;59(7):1765-1770. doi:10.2337/db09-1414

38. Qin X, Shen H, Liu M, et al. GLP-1 reduces intestinal lymph flow, triglyceride absorption, and apolipoprotein production in rats. Am J Physiol Gastrointest Liver Physiol. 2005;288(5): G943-949. doi:10.1152/ajpgi.00303.2004

39. Deane AM, Nguyen NQ, Stevens JE, et al. Endogenous glucagon-like peptide-1 slows gastric emptying in healthy subjects, attenuating postprandial glycemia. $J$ Clin Endocrinol Metab. 2010;95(1):215-221. doi:10.1210/jc.2009-1503

40. Wu T, Rayner CK, Horowitz M. Incretins. Handb Exp Pharmacol. 2016;233:137-171.

41. Moran TH, Smedh U, Kinzig KP, et al. (3-36) inhibits gastric emptying and produces acute reductions in food intake in rhesus monkeys. Am J Physiol Regul Integr Comp Physiol. 2005;288(2): R384-388. doi:10.1152/ajpregu.00535.2004

42. Feng Y, Wang Y, Wang P, Huang Y, Wang F. Short-chain fatty acids manifest stimulative and protective effects on intestinal barrier function through the inhibition of NLRP3 inflammasome and autophagy. Cell Physiol Biochem. 2018;49(1):190-205. doi:10.1159/000492853

43. Koeth RA, Wang Z, Levison BS, et al. Intestinal microbiota metabolism of L-carnitine, a nutrient in red meat, promotes atherosclerosis. Nat Med. 2013;19(5):576-585. doi:10.1038/ nm. 3145

44. Romano KA, Vivas EI, Amador-Noguez D, Rey FE. Intestinal microbiota composition modulates choline bioavailability from diet and accumulation of the proatherogenic metabolite trimethylamine-N-oxide. mBio. 2015;6(2):e02481. doi:10.1128/ mBio.02481-14

45. Chen Y, Weng Z, Liu Q, et al. FMO3 and its metabolite TMAO contribute to the formation of gallstones. Biochim Biophys Acta Mol Basis Dis. 2019;1865(10):2576-2585. doi:10.1016/j. bbadis.2019.06.016

46. Lever M, Slow S. The clinical significance of betaine, an osmolyte with a key role in methyl group metabolism. Clin Biochem. 2010;43(9):732-744. doi:10.1016/j.clinbiochem.2010.03.009 
47. Lent-Schochet D, Silva R, McLaughlin M, Huet B, Jialal I. Changes to trimethylamine-N-oxide and its precursors in nascent metabolic syndrome. Horm Mol Biol Clin Investig. 2018;35(2). doi: 10.1515/hmbci-2018-0015.

48. Randrianarisoa E, Lehn-Stefan A, Wang X, et al. Relationship of serum trimethylamine N-Oxide (TMAO) levels with early atherosclerosis in humans. Sci Rep. 2016;6:26745. doi:10.1038/ srep26745

49. Li XS, Obeid S, Klingenberg R, et al. Gut microbiota-dependent trimethylamine $\mathrm{N}$-oxide in acute coronary syndromes: a prognostic marker for incident cardiovascular events beyond traditional risk factors. Eur Heart J. 2017;38(11):814-824. doi:10.1093/eurheartj/ehw582

50. Li J, Tan Y, Zhou P, et al. Association of Trimethylamine $\mathrm{N}$-Oxide levels and calcification in culprit lesion segments in patients with ST-segment-elevation myocardial infarction evaluated by optical coherence tomography. Front Cardiovasc Med. 2021;8:628471. doi:10.3389/fcvm.2021.628471

51. Ding L, Chang M, Guo Y, et al. Trimethylamine-N-oxide (TMAO)-induced atherosclerosis is associated with bile acid metabolism. Lipids Health Dis. 2018;17(1):286. doi:10.1186/ s12944-018-0939-6

52. Sun X, Jiao X, Ma Y, et al. Trimethylamine N-oxide induces inflammation and endothelial dysfunction in human umbilical vein endothelial cells via activating ROS-TXNIP-NLRP3 inflammasome. Biochem Biophys Res Commun. 2016;481(12):63-70. doi:10.1016/j.bbrc.2016.11.017

53. Govindarajulu M, Pinky PD, Steinke I, et al. Gut metabolite TMAO induces synaptic plasticity deficits by promoting endoplasmic reticulum stress. Front Mol Neurosci. 2020;13:138. doi:10.3389/fnmol.2020.00138

54. McGlone ER, Bloom SR. Bile acids and the metabolic syndrome. Ann Clin Biochem. 2019;56(3):326-337. doi:10.1177/ 0004563218817798

55. Rajani C, Jia W. Bile acids and their effects on diabetes. Front Med. 2018;12(6):608-623. doi:10.1007/s11684-018-0644-x

56. van de Peppel IP, Verkade HJ, Jonker JW. Metabolic consequences of ileal interruption of the enterohepatic circulation of bile acids. Am J Physiol Gastrointest Liver Physiol. 2020;319(5): G619-g625. doi:10.1152/ajpgi.00308.2020

57. González-Regueiro JA, Moreno-Castañeda L, Uribe M, ChávezTapia NC. The role of bile acids in glucose metabolism and their relation with diabetes. Ann Hepatol. 2017;16(Suppl. 1: s3105.):16-21. doi:10.5604/01.3001.0010.5672

58. Ali AH, Carey EJ, Lindor KD. Recent advances in the development of farnesoid X receptor agonists. Ann Transl Med. 2015;3 (1):5. doi:10.3978/j.issn.2305-5839.2014.12.06

59. Xie C, Huang W, Young RL, et al. Role of bile acids in the regulation of food intake, and their dysregulation in metabolic disease. Nutrients. 2021;13(4):1104. doi:10.3390/nu13041104

60. Trabelsi MS, Daoudi M, Prawitt J, et al. Farnesoid X receptor inhibits glucagon-like peptide-1 production by enteroendocrine $\mathrm{L}$ cells. Nat Commun. 2015;6:7629. doi:10.1038/ncomms8629

61. Deutschmann K, Reich M, Klindt C, et al. Bile acid receptors in the biliary tree: TGR5 in physiology and disease. Biochim Biophys Acta Mol Basis Dis. 2018;1864(4 Pt B):1319-1325. doi:10.1016/j.bbadis.2017.08.021

62. Katsuma S, Hirasawa A, Tsujimoto G. Bile acids promote glucagon-like peptide-1 secretion through TGR5 in a murine enteroendocrine cell line STC-1. Biochem Biophys Res Commun. 2005;329(1):386-390. doi:10.1016/j.bbrc.2005.01.139

63. Yang H, Liu H, Jiao Y, Qian J. Roux-en-Y gastrointestinal bypass promotes activation of TGR5 and peptide YY. Endocr Metab Immune Disord Drug Targets. 2020;20(8):1262-1267. doi:10.2174/1871530320666200628024500
64. Duca FA, Côté CD, Rasmussen BA, et al. Metformin activates a duodenal Ampk-dependent pathway to lower hepatic glucose production in rats. Nat Med. 2015;21(5):506-511. doi:10.1038/ nm.3787

65. McCreight LJ, Bailey CJ, Pearson ER. Metformin and the gastrointestinal tract. Diabetologia. 2016;59(3):426-435. doi:10.1007/ s00125-015-3844-9

66. Hur KY, Lee MS. New mechanisms of metformin action: focusing on mitochondria and the gut. J Diabetes Investig. 2015;6 (6):600-609. doi:10.1111/jdi.12328

67. Lee H, Ko G. Effect of metformin on metabolic improvement and gut microbiota. Appl Environ Microbiol. 2014;80(19):5935-5943. doi:10.1128/AEM.01357-14

68. Elbere I, Kalnina I, Silamikelis I, et al. Association of metformin administration with gut microbiome dysbiosis in healthy volunteers. PLoS One. 2018;13(9):e0204317. doi:10.1371/journal.pone.0204317

69. Bryrup T, Thomsen CW, Kern T, et al. Metformin-induced changes of the gut microbiota in healthy young men: results of a non-blinded, one-armed intervention study. Diabetologia. 2019;62(6):1024-1035. doi:10.1007/s00125-019-4848-7

70. Elbere I, Silamikelis I, Dindune II, et al. Baseline gut microbiome composition predicts metformin therapy short-term efficacy in newly diagnosed type 2 diabetes patients. PLoS One. 2020;15 (10):e0241338. doi:10.1371/journal.pone.0241338

71. Nakajima H, Takewaki F, Hashimoto Y, et al. The effects of metformin on the gut microbiota of patients with type 2 diabetes: a two-center, Quasi-Experimental Study. Life. 2020;10(9). doi:10.3390/life10090195

72. de la Cuesta-zuluaga J, Mueller NT, Corrales-Agudelo V, et al. Metformin is associated with higher relative abundance of mucin-degrading akkermansia muciniphila and several short-chain fatty acid-producing microbiota in the gut. Diabetes Care. 2017;40(1):54-62. doi:10.2337/dc16-1324

73. Kuka J, Videja M, Makrecka-Kuka M, et al. Metformin decreases bacterial trimethylamine production and trimethylamine N-oxide levels in db/db mice. Sci Rep. 2020;10(1):14555. doi:10.1038/ s41598-020-71470-4

74. Sansome DJ, Xie C, Veedfald S, Horowitz M, Rayner CK, Wu T. Mechanism of glucose-lowering by metformin in type 2 diabetes: role of bile acids. Diabetes Obes Metab. 2020;22(2):141-148. doi:10.1111/dom.13869

75. Sun L, Xie C, Wang G, et al. Gut microbiota and intestinal FXR mediate the clinical benefits of metformin. Nat Med. 2018;24 (12):1919-1929. doi:10.1038/s41591-018-0222-4

76. Forslund K, Hildebrand F, Nielsen T, et al. Disentangling type 2 diabetes and metformin treatment signatures in the human gut microbiota. Nature. 2015;528(7581):262-266. doi:10.1038/ nature 15766

77. Liu Z, Ma S. Recent advances in synthetic $\alpha$-glucosidase inhibitors. ChemMedChem. 2017;12(11):819-829. doi:10.1002/ cmdc. 201700216

78. Smith BJ, Miller RA, Ericsson AC, Harrison DC, Strong R, Schmidt TM. Changes in the gut microbiome and fermentation products concurrent with enhanced longevity in acarbose-treated mice. BMC Microbiol. 2019;19(1):130. doi:10.1186/s12866-0191494-7

79. Xu GD, Cai L, Ni YS, et al. Comparisons of effects on intestinal short-chain fatty acid concentration after exposure of two glycosidase inhibitors in mice. Biol Pharm Bull. 2018;41 (7):1024-1033. doi:10.1248/bpb.b17-00978

80. Baxter NT, Lesniak NA, Sinani H, Schloss PD, Koropatkin NM. The glucoamylase inhibitor acarbose has a diet-dependent and reversible effect on the murine gut microbiome. mSphere. 2019;4(1):e00528-18. 
81. Zhang X, Fang Z, Zhang C, et al. Effects of acarbose on the gut microbiota of prediabetic patients: a randomized, double-blind, controlled crossover trial. Diabetes Ther. 2017;8(2):293-307. doi:10.1007/s13300-017-0226-y

82. Su B, Liu H, Li J, et al. Acarbose treatment affects the serum levels of inflammatory cytokines and the gut content of bifidobacteria in Chinese patients with type 2 diabetes mellitus. $J$ Diabetes. 2015;7(5):729-739. doi:10.1111/1753-0407.12232

83. Gu Y, Wang X, Li J, et al. Analyses of gut microbiota and plasma bile acids enable stratification of patients for antidiabetic treatment. Nat Commun. 2017;8(1):1785. doi:10.1038/s41467017-01682-2

84. Soccio RE, Chen ER, Lazar MA. Thiazolidinediones and the promise of insulin sensitization in type 2 diabetes. Cell Metab. 2014;20(4):573-591. doi:10.1016/j.cmet.2014.08.005

85. Nanjan MJ, Mohammed M, Prashantha Kumar BR, Chandrasekar MJN. Thiazolidinediones as antidiabetic agents: a critical review. Bioorg Chem. 2018;77:548-567. doi:10.1016/j. bioorg.2018.02.009

86. Fajas L, Auboeuf D, Raspé E, et al. The organization, promoter analysis, and expression of the human PPARgamma gene. J Biol Chem. 1997;272(30):18779-18789. doi:10.1074/jbc.272.30.18779

87. Madsen MSA, Grønlund RV, Eid J, et al. Characterization of local gut microbiome and intestinal transcriptome responses to rosiglitazone treatment in diabetic $\mathrm{db} / \mathrm{db}$ mice. Biomed Pharmacother. 2021;133:110966. doi:10.1016/j.biopha.2020.110966

88. $\mathrm{Xu} \mathrm{P}$, Hong $\mathrm{F}$, Wang $\mathrm{J}$, et al. DBZ is a putative PPAR $\gamma$ agonist that prevents high fat diet-induced obesity, insulin resistance and gut dysbiosis. Biochim Biophys Acta Gen Subj. 2017;1861(11 Pt A):2690-2701. doi:10.1016/j.bbagen.2017.07.013

89. Garcia-Beltran C, Malpique R, Carbonetto B, et al. Gut microbiota in adolescent girls with polycystic ovary syndrome: effects of randomized treatments. Pediatr Obes. 2021;16(4):e12734. doi:10.1111/ijpo.12734

90. Drucker DJ, Nauck MA. The incretin system: glucagon-like peptide- 1 receptor agonists and dipeptidyl peptidase- 4 inhibitors in type 2 diabetes. Lancet. 2006;368(9548):1696-1705. doi:10.1016/S0140-6736(06)69705-5

91. Gilbert MP, Pratley RE. GLP-1 analogs and DPP-4 inhibitors in type 2 diabetes therapy: review of head-to-head clinical trials. Front Endocrinol (Lausanne). 2020;11:178. doi:10.3389/fendo.2020.00178

92. Meier JJ. GLP-1 receptor agonists for individualized treatment of type 2 diabetes mellitus. Nat Rev Endocrinol. 2012;8 (12):728-742. doi:10.1038/nrendo.2012.140

93. Zhao L, Chen Y, Xia F, et al. A glucagon-like peptide-1 receptor agonist lowers weight by modulating the structure of gut microbiota. Front Endocrinol (Lausanne). 2018;9:233. doi: $10.3389 /$ fendo. 2018.00233

94. Zhang Q, Xiao X, Zheng J, et al. Featured article: structure moderation of gut microbiota in liraglutide-treated diabetic male rats. Exp Biol Med (Maywood). 2018;243(1):34-44. doi:10.1177/ 1535370217743765

95. Shang J, Liu F, Zhang B, et al. Liraglutide-induced structural modulation of the gut microbiota in patients with type 2 diabetes mellitus. PeerJ. 2021;9:e11128. doi:10.7717/peerj.11128

96. Zhang N, Tao J, Gao L, et al. Liraglutide attenuates nonalcoholic fatty liver disease by modulating gut microbiota in rats administered a high-fat diet. Biomed Res Int. 2020;2020:2947549. doi:10.1155/2020/2947549

97. Moreira GV, Azevedo FF, Ribeiro LM, et al. Liraglutide modulates gut microbiota and reduces NAFLD in obese mice. J Nutr Biochem. 2018;62:143-154. doi:10.1016/j.jnutbio.2018.07.009

98. Wismann P, Pedersen SL, Hansen G, et al. Novel GLP-1/GLP-2 co-agonists display marked effects on gut volume and improves glycemic control in mice. Physiol Behav. 2018;192:72-81. doi:10.1016/j.physbeh.2018.03.004
99. Madsen MSA, Holm JB, Pallejà A, et al. Metabolic and gut microbiome changes following GLP-1 or dual GLP-1/GLP-2 receptor agonist treatment in diet-induced obese mice. Sci Rep. 2019;9(1):15582. doi:10.1038/s41598-019-52103-x

100. Deacon CF. Dipeptidyl peptidase 4 inhibitors in the treatment of type 2 diabetes mellitus. Nat Rev Endocrinol. 2020;16 (11):642-653. doi:10.1038/s41574-020-0399-8

101. Liao X, Song L, Zeng B, et al. Alteration of gut microbiota induced by DPP-4i treatment improves glucose homeostasis. EBioMedicine. 2019;44:665-674. doi:10.1016/j. ebiom.2019.03.057

102. Yan X, Feng B, Li P, Tang Z, Wang L. Microflora disturbance during progression of glucose intolerance and effect of sitagliptin: an Animal Study. $J$ Diabetes Res. 2016;2016:2093171. doi:10.1155/2016/2093171

103. Olivares M, Neyrinck AM, Pötgens SA, et al. The DPP-4 inhibitor vildagliptin impacts the gut microbiota and prevents disruption of intestinal homeostasis induced by a Western diet in mice. Diabetologia. 2018;61(8):1838-1848. doi:10.1007/s00125-0184647-6

104. Chen J, Williams S, Ho S, et al. Quantitative PCR tissue expression profiling of the human SGLT2 gene and related family members. Diabetes Ther. 2010;1(2):57-92. doi:10.1007/s13300010-0006-4

105. van Bommel EJ, Muskiet MH, Tonneijck L, Kramer MH, Nieuwdorp M, van Raalte DH. SGLT2 inhibition in the diabetic kidney-from mechanisms to clinical outcome. Clin J Am Soc Nephrol. 2017;12(4):700-710. doi:10.2215/CJN.06080616

106. Poulsen SB, Fenton RA, Rieg T. Sodium-glucose cotransport. Curr Opin Nephrol Hypertens. 2015;24(5):463-469. doi:10.1097/MNH.0000000000000152

107. Lee DM, Battson ML, Jarrell DK, et al. SGLT2 inhibition via dapagliflozin improves generalized vascular dysfunction and alters the gut microbiota in type 2 diabetic mice. Cardiovasc Diabetol. 2018;17(1):62. doi:10.1186/s12933-018-0708-x

108. Herat LY, Ward NC, Magno AL, et al. Sodium glucose co-transporter 2 inhibition reduces succinate levels in diabetic mice. World J Gastroenterol. 2020;26(23):3225-3235. doi:10.3748/wjg.v26.i23.3225

109. Matsumoto M, Suzuma K, Maki T, et al. Succinate increases in the vitreous fluid of patients with active proliferative diabetic retinopathy. Am J Ophthalmol. 2012;153(5):896-902.e891. doi:10.1016/j.ajo.2011.10.006

110. van Bommel EJM, Herrema H, Davids M, Kramer MHH, Nieuwdorp M, van Raalte DH. Effects of 12-week treatment with dapagliflozin and gliclazide on faecal microbiome: results of a double-blind randomized trial in patients with type 2 diabetes. Diabetes Metab. 2020;46(2):164-168. doi:10.1016/j. diabet.2019.11.005

111. Kuo GH, Gaul MD, Liang Y, et al. Synthesis and biological evaluation of benzocyclobutane-C-glycosides as potent and orally active SGLT1/SGLT2 dual inhibitors. Bioorg Med Chem Lett. 2018;28(7):1182-1187. doi:10.1016/j.bmcl.2018.02.057

112. Du F, Hinke SA, Cavanaugh C, et al. Potent sodium/glucose cotransporter SGLT1/2 dual inhibition improves glycemic control without marked gastrointestinal adaptation or colonic microbiota changes in rodents. J Pharmacol Exp Ther. 2018;365(3):676-687. doi:10.1124/jpet.118.248575

113. Tian J, Jin D, Bao Q, et al. Evidence and potential mechanisms of traditional Chinese medicine for the treatment of type 2 diabetes: a systematic review and meta-analysis. Diabetes Obes Metab. 2019;21(8):1801-1816. doi:10.1111/dom.13760

114. Zheng Y, Ding Q, Wei Y, et al. Effect of traditional Chinese medicine on gut microbiota in adults with type 2 diabetes: a systematic review and meta-analysis. Phytomedicine. 2020;88:153455. doi:10.1016/j.phymed.2020.153455 
115. Zhao F, Liu Q, Cao J, et al. A sea cucumber (Holothuria leucospilota) polysaccharide improves the gut microbiome to alleviate the symptoms of type 2 diabetes mellitus in Goto-Kakizaki rats. Food Chem Toxicol. 2020;135:110886. doi:10.1016/j. fct.2019.110886

116. Liu G, Liang L, Yu G, Li Q. Pumpkin polysaccharide modifies the gut microbiota during alleviation of type 2 diabetes in rats. Int $J$ Biol Macromol. 2018;115:711-717. doi:10.1016/j. ijbiomac.2018.04.127

117. Cheng Y, Sibusiso L, Hou L, et al. Sargassum fusiforme fucoidan modifies the gut microbiota during alleviation of streptozotocin-induced hyperglycemia in mice. Int J Biol Macromol. 2019;131:1162-1170. doi:10.1016/j.ijbiomac.2019.04.040

118. Chen C, You LJ, Huang Q, et al. Modulation of gut microbiota by mulberry fruit polysaccharide treatment of obese diabetic $\mathrm{db} / \mathrm{db}$ mice. Food Funct. 2018;9(7):3732-3742. doi:10.1039/ C7FO01346A

119. Chen LC, Fan ZY, Wang HY, Wen DC, Zhang SY. Effect of polysaccharides from adlay seed on anti-diabetic and gut microbiota. Food Funct. 2019;10(7):4372-4380. doi:10.1039/ $\mathrm{C} 9 \mathrm{FO} 00406 \mathrm{H}$

120. Chen M, Lu B, Li Y, et al. Metabolomics insights into the modulatory effects of long-term compound polysaccharide intake in high-fat diet-induced obese rats. Nutr Metab (Lond). 2018;15:8. doi:10.1186/s12986-018-0246-2

121. Liu Y, Lai G, Guo Y, et al. Protective effect of Ganoderma lucidum spore extract in trimethylamine-N-oxide-induced cardiac dysfunction in rats. J Food Sci. 2021;86(2):546-562. doi:10.1111/ 1750-3841.15575

122. Zhang $\mathrm{CH}$, Sheng JQ, Sarsaiya S, et al. The anti-diabetic activities, gut microbiota composition, the anti-inflammatory effects of Scutellaria-coptis herb couple against insulin resistance-model of diabetes involving the toll-like receptor 4 signaling pathway. $J \quad$ Ethnopharmacol. 2019;237:202-214. doi:10.1016/j.jep.2019. 02.040

123. Xiao S, Liu C, Chen M, et al. Scutellariae radix and coptidis rhizoma ameliorate glycolipid metabolism of type 2 diabetic rats by modulating gut microbiota and its metabolites. Appl Microbiol Biotechnol. 2020;104(1):303-317. doi:10.1007/s00253-01910174-w

124. Zhang B, Yue R, Chen $\mathrm{Y}$, et al. The herbal medicine scutellaria-coptis alleviates intestinal mucosal barrier damage in diabetic rats by inhibiting inflammation and modulating the gut microbiota. Evid Based Complement Alternat Med. 2020;2020:4568629. doi:10.1155/2020/4568629

125. Shin NR, Gu N, Choi HS, Kim H. Combined effects of Scutellaria baicalensis with metformin on glucose tolerance of patients with type 2 diabetes via gut microbiota modulation. Am J Physiol Endocrinol Metab. 2020;318(1):E52-e61. doi:10.1152/ ajpendo.00221.2019

126. Yang G, Lin CC, Yang Y, et al. Nobiletin prevents trimethylamine oxide-induced vascular inflammation via inhibition of the NF- $\kappa \mathrm{B} /$ MAPK pathways. J Agric Food Chem. 2019;67(22):6169-6176. doi:10.1021/acs.jafc. 9 b01270
127. Wang K, Feng X, Chai L, Cao S, Qiu F. The metabolism of berberine and its contribution to the pharmacological effects. Drug Metab Rev. 2017;49(2):139-157. doi:10.1080/ 03602532.2017 .1306544

128. Habtemariam S. Berberine pharmacology and the gut microbiota: a hidden therapeutic link. Pharmacol Res. 2020;155:104722. doi:10.1016/j.phrs.2020.104722

129. Zhu L, Zhang D, Zhu H, et al. Berberine treatment increases Akkermansia in the gut and improves high-fat diet-induced atherosclerosis in Apoe(-/-) mice. Atherosclerosis. 2018;268:117-126. doi:10.1016/j.atherosclerosis.2017.11.023

130. Li X, Su C, Jiang Z, et al. Berberine attenuates choline-induced atherosclerosis by inhibiting trimethylamine and trimethylamine-N-oxide production via manipulating the gut microbiome. NPJ Biofilms Microbiomes. 2021;7(1):36. doi:10.1038/s41522-021-00205-8

131. Wu M, Yang S, Wang S, et al. Effect of berberine on atherosclerosis and gut microbiota modulation and their correlation in high-fat diet-fed ApoE-/- Mice. Front Pharmacol. 2020;11:223. doi:10.3389/fphar.2020.00223

132. Dou Y, Huang R, Li Q, et al. Oxyberberine, an absorbed metabolite of berberine, possess superior hypoglycemic effect via regulating the PI3K/Akt and Nrf2 signaling pathways. Biomed Pharmacother. 2021;137:111312. doi:10.1016/j. biopha.2021.111312

133. Zhang $\mathrm{W}, \mathrm{Xu} \mathrm{JH}, \mathrm{Yu} \mathrm{T}$, Chen QK. Effects of berberine and metformin on intestinal inflammation and gut microbiome composition in $\mathrm{db} / \mathrm{db}$ mice. Biomed Pharmacother. 2019;118:109131. doi:10.1016/j.biopha.2019.109131

134. Zhang X, Zhao Y, Zhang M, et al. Structural changes of gut microbiota during berberine-mediated prevention of obesity and insulin resistance in high-fat diet-fed rats. PLoS One. 2012;7(8): e42529. doi:10.1371/journal.pone.0042529

135. Liu D, Zhang Y, Liu Y, et al. Berberine modulates gut microbiota and reduces insulin resistance via the TLR4 signaling pathway. Exp Clin Endocrinol Diabetes. 2018;126(8):513-520. doi:10.1055/s-0043-125066

136. Wang Y, Liu H, Zheng M, et al. Berberine slows the progression of prediabetes to diabetes in Zucker diabetic fatty rats by enhancing intestinal secretion of glucagon-like peptide-2 and improving the gut microbiota. Front Endocrinol (Lausanne). 2021;12:609134. doi:10.3389/fendo.2021.609134

137. Li M, Zhou W, Dang Y, Li C, Ji G, Zhang L. Berberine compounds improves hyperglycemia via microbiome mediated colonic TGR5-GLP pathway in $\mathrm{db} / \mathrm{db}$ mice. Biomed Pharmacother. 2020;132:110953. doi:10.1016/j.biopha.2020.110953

138. Zhang Y, Gu Y, Ren H, et al. Gut microbiome-related effects of berberine and probiotics on type 2 diabetes (the PREMOTE study). Nat Commun. 2020;11(1):5015. doi:10.1038/s41467-02018414-8

\section{Publish your work in this journal}

Drug Design, Development and Therapy is an international, peerreviewed open-access journal that spans the spectrum of drug design and development through to clinical applications. Clinical outcomes, patient safety, and programs for the development and effective, safe, and sustained use of medicines are a feature of the journal, which has also been accepted for indexing on PubMed Central. The manuscript management system is completely online and includes a very quick and fair peer-review system, which is all easy to use. Visit http://www. dovepress.com/testimonials.php to read real quotes from published authors. 